\title{
La comunicación como instrumento de cambio en la problemática ambiental
}

\section{Communication as an instrument of change in environmental problems}

\author{
Azucena Wendy Montalva Miñan* \\ Escuela Profesional de Ciencias de la Comunicación, \\ Universidad de San Martín de Porres, Perú
}

\section{Resumen}

Se analiza la capacidad transformadora de la comunicación frente a la crisis ecológica que atraviesa el mundo en la actualidad. La comunicación como creadora de cultura tiene la loable misión de establecer nuevos valores y hábitos respecto del medio ambiente, así como interés en la comprensión y vivencia de los temas medioambientales en favor del entorno natural. La comunicación y el medio ambiente son temas que confluyen en la construcción de sociedades urbanas con soporte ético, fomentando una actitud social beneficiosa frente a la problemática ambiental. Todo proceso comunicativo tiene vital importancia en la sociedad ya que es un determinante fundamental en la educación, para fomentar valores, compromiso y responsabilidad frente al bien común y el cuidado medioambiental.

Palabras clave: comunicación; medio ambiente; cultura; valores; hábitos

\begin{abstract}
This article analyzes the transformative capacity of communication in the face of the ecological crisis that the world is going through today. Communication as culture maker has the laudable mission of establishing new values and habits regarding the environment, with the aim of raising interest
\end{abstract}

Este es un artículo Open Access bajo la licencia Creative Commons Atribución-NoComercial-Compartirlgual 4.0 
in understanding and experiencing environmental issues in favor of the natural environment. Communication and environment are topics that converge in the construction of urban societies with ethical support, fostering a favorable social attitude towards environmental issues. Every communication process is of vital importance in society since it is a fundamental element in education to promote values, commitment and responsibility towards the common good and, in this particular case, environmental care.

Keywords: communication; environment; culture; values; habits

\section{Introducción}

El medio ambiente registra gran deterioro en la actualidad como consecuencia de la falta de compromiso personal y social, que conlleva a resultados devastadores para la humanidad, como el cambio climático que afecta la condición de vida de las personas. Es allí donde la comunicación medioambiental surge como herramienta educadora y sensibilizadora para ayudar a plasmar nuevos hábitos proambientales en las conductas de los seres humanos en favor de la preservación ambiental.

Siendo este un problema social requiere de la concientización y sensibilización de la sociedad para la protección del entorno natural. Al respecto en la Ley general del ambiente se señala:

Toda persona tiene el derecho irrenunciable a vivir en un ambiente saludable, equilibrado y adecuado para el pleno desarrollo de la vida, y el deber de contribuir a una efectiva gestión ambiental y de proteger el ambiente, así como sus componentes, asegurando particularmente la salud de las personas en forma individual y colectiva, la conservación de la diversidad biológica, el aprovechamiento sostenible de los recursos naturales y el desarrollo sostenible del país. (Sociedad Peruana de Derecho Ambiental, 2006)

En Perú, el 20 de diciembre de 2018, se promulgo la ley de plásticos que busca acabar con los plásticos de un solo uso, generando así una actitud positiva de parte de la población frente a la conservación ambiental, apostando 
por educarse en la responsabilidad del uso de bolsas plásticas. Los problemas ambientales necesitan ser comunicados a la sociedad con la finalidad de buscar una solución, cambiando comportamientos, normas y costumbres culturales e incentivando la protección de la naturaleza mediante hábitos ambientales que lleven a una transformación a nivel global. Todo esto se logra mediante la comunicación, informando y educando, creando y transmitiendo cultura $\mathrm{y}$, sobre todo, teniendo como finalidad influir en el cambio de la conducta humana. La comunicación es la gran transmisora de cultura que ayuda a persuadir en valores, actitudes, conductas y hábitos en favor de la ecología.

Por tanto, la comunicación tiene utilidad estratégica, es decir, contribuye a informar, instruir y sensibilizar a los ciudadanos protagonistas del cambio en favor del entorno natural, con miras a dejar un territorio sostenible para las generaciones siguientes.

Existen muchas definiciones y teorías acerca de la comunicación ambiental que utilizan estrategias comunicacionales enfocadas al cambio de comportamiento. Por ejemplo, para Oepen la comunicación ambiental es «el planteamiento y uso estratégico de procesos de comunicación y utilización de medios para apoyar la toma de decisiones, la participación pública y la implementación de proyectos para lograr el desarrollo sostenible» (como se citó en Roger \& Buil, 2014, p. 23).

Coincidiendo con lo anterior, considero a la comunicación como el mecanismo orientador de conductas sostenibles y como el método de acción para llevar a cabo un plan de formación en contenidos que favorezcan el cuidado y preservación ambiental. Visto así, la propuesta que presento en este estudio consiste en fomentar nuevas prácticas ecológicas en la sociedad que comiencen por la educación como eje principal al comunicar y dar a conocer información medioambiental. Estrategias de comunicación e información educativa medioambiental son los dos factores que se combinarán para dar mayor fuerza al mensaje.

\section{La comunicación como portadora de educación}

El objetivo principal de toda comunicación es persuadir dentro de su mensaje. Este mensaje, además de ser claro, debe favorecer una interacción 
de enseñanzas y aprendizajes. Interacción que será influyente en la medida que genere procesos educativos en sus mensajes y que modifique el pensamiento y la conducta del receptor.

La necesidad de establecer un sistema educativo donde el eje sea la comunicación en todas sus dimensiones, radica en fomentar la capacidad crítica y la interacción en los problemas medioambientales. La comunicación en estos temas busca educar y sensibilizar sobre la importancia de los comportamientos responsables que favorecen al entorno natural, desarrollando prácticas ecológicas enfocadas en la conservación ambiental. Para Roger y Bui (2014) se pasa de una «actividad relacional, a una realidad dialógica, es decir, se trata de un proceso bidireccional, que va más allá del simple hecho de transmitir información» (p. 23). Por lo tanto, la comunicación tiene la función de orientar el desarrollo de prácticas encaminadas al cuidado del entorno, acrecentando el conocimiento sobre determinados factores de contaminación ambiental, persuadiendo a la gente a adoptar conductas ambientales cotidianas, como la compra de productos en bolsas de tela, reciclaje de residuos, ahorro de energía y agua, entre otros.

Con lo cual, la comunicación es un aporte positivo frente a los problemas ambientales ya que «los medios de comunicación tienden a desarrollar competencias adecuadas y procesos mentales especializados que facilitan una labor de aprendizaje a través de ellos» (Quiroz-Velasco, 1997, p. 37).

Otro aspecto a considerarse en un proceso de comunicación, cuyo fin es el de educar en comportamientos ecológicos, es tomar conocimiento que dicho proceso no es fácil. Por ello, es necesario contar con estrategias de comunicación eficaces que conduzcan a la población al cambio de ciertas conductas que llevan realizando por mucho tiempo creyendo que son correctas. Modificarlas y corregirlas requiere de tiempo, no obstante, una comunicación bien planificada puede lograrlo.

La educación ambiental debe iniciarse en las familias, centros educativos y centros laborales, enseñando a las personas a tomar conciencia del daño ambiental que se viene generando. La comunicación educativa comprometida con el cuidado del medio ambiente ayudará a que se desarrollen valores que repercutan en el cuidado de la vida, beneficiando la salud de las personas. Para 
ello, los medios de comunicación tienen que asumir el compromiso social de mantener informada a la población sobre los avances en cuanto a calidad de vida.

\section{Comunicando una cultura ambiental}

El ser humano plasma dentro de una comunidad un modo de vida, que se llama cultura y que reune todo lo que el hombre transmite. Así podemos señalar que «el concepto de cultura comprende las muy diversas formas en que los colectivos humanos trasmiten y aprenden un conjunto de conocimientos que les permiten mantener un orden social» (Méndez, 2014, p. 39). El ser humano cuando comunica crea cultura, y mediante esta, influye en la conducta humana, estableciendo nuevos valores, es aquí donde el tema medioambiental se debe aplicar, ya que la comunicación es una herramienta para difundir los conocimientos a la población en asuntos medioambientales y para realizar una sensibilización generadora de cambios en la conducta frente a la custodia medioambiental. En este sentido, Martínez y Ramos (2003) plantean:

El desarrollo de una cultura ambiental supone un cambio de concepción del hombre sobre sí mismo y sobre su lugar en el mundo, y consecuentemente de su lugar respecto con los otros hombres, con la sociedad y con la naturaleza. Debe apropiarse del conocimiento de una realidad compleja, aprender a interaccionar con ella de otro modo, pero sobre todo debe reorientar sus fines, sin abandonarlos. Considerar al hombre como individuo, especie y miembro de grupos sociales, lo incorpora al mundo desde ámbitos múltiples. (p. 1)

Por su parte, el ser humano al relacionarse en la sociedad crea cultura que impacta de una manera particular en los recursos naturales de forma positiva pero también negativa; se plasman los valores, comportamientos y creencias. En la sociedad se desarrolla una identidad cultural influenciada por los mensajes comunicativos vertidos por los medios de comunicación que tienen un rol importante como transmisores de cultura. Teniendo en claro el concepto de cultura y su expresión en la sociedad, debemos reflexionar y tomar conciencia de nuestro comportamiento, sobre todo en temas 
medioambientales, ya que lo que se busca es impulsar un cambio de actitud que defienda y favorezca la preservación y sostenibilidad medioambiental, y que además se transmita de generación en generación. Es la educación, mediante buenos contenidos comunicativos y buenos modelos, la encargada de construir y orientar las acciones que se conviertan en hábitos proambientales para contribuir a mejorar la realidad del medio ambiente.

Cultura y naturaleza se interrelacionan, en la cultura se configura el actuar humano en favor o en contra del medio ambiente; despilfarro, contaminación del agua, expulsión de los desechos en las calles y la falta hábitos de reciclaje en los hogares ocurren en una cultura antiecológica que vive desconsiderando a la naturaleza, explotándola e ignorando las acciones sostenibles que favorezcan a las generaciones futuras. La cultura es creada por el hombre y solo el hombre tiene la gran tarea de transformarla.

\section{La comunicación de la problemática ambiental}

La comunicación es primordial para conducir a la sociedad a tomar conciencia de la problemática ambiental que se vive, con el fin de que las nuevas generaciones custodien el agua, reduzcan la contaminación del aire, reutilicen y reciclen; por lo que es necesario que a través de los medios de comunicación se realice una educación ambiental, donde se informe y capacite sobre la actual situación ambiental. Todos estos cambios actitudinales se reflejarán en nuevas acciones cotidianas ecológicas que ayuden a preservar el entorno natural. Aparicio (2016) refiere lo siguiente sobre la comunicación de la problemática ambiental:

Promueve procesos de toma de decisiones sociales sobre el manejo de ecosistemas mediante el involucramiento de los actores relacionados con una problemática particular, de la apropiación de responsabilidades de grupos que se benefician de estos sistemas naturales y de la cooperación de los actores clave y de la población en general, con el fin de negociar soluciones y de influir en las políticas que inciden en dicha problemática, profundizando en la búsqueda de acuerdos sectoriales. (p. 227) 
Los problemas ecológicos merecen ser reflexionados mediante una adecuada comunicación que conlleve al entendimiento y a la predisposición de buenos hábitos ambientales sostenibles en el tiempo.

La problemática ambiental se comienza a resolver, en primer lugar, con el autorreconocimiento de ser parte de la naturaleza, y como consecuencia las acciones tienen un efecto sobre el mundo. La comunicación debe orientar a los ciudadanos a comprometerse con el cuidado ambiental vertiendo en cada acción valores que aporten en la edificación de una sociedad más responsable con el entorno natural. Debemos conocer que una sociedad está dentro de un entorno cultural que la sostiene «en donde el proceso de comunicación permite o activa la elaboración de la representación de los objetos de referencia, de las mediaciones o de los elementos contenidos en la misma cultura» (Carabaza, 2006, p. 93).

Por lo tanto, en la comunicación de los problemas ambientales es posible generar elementos que logren una sociedad que comience a interesarse por hábitos y actitudes ecológicas sostenibles, como producto de un efectivo proceso de comunicación cuyo objetivo es el cuidado y la prevención del medio ambiente.

Los procesos de comunicación ambiental, que se lleven a cabo, deben contener mensajes repetitivos que fomenten un cambio ecológico logrando generar transformaciones culturales que cambien pensamientos y comportamientos en favor del medio ambiente.

Así, se contribuye a encontrar armonía con la naturaleza mediante esta programación de hábitos ambientales, y como consecuencia, las conductas ecológicas responsables reducirán la contaminación, incentivarán el reúso, el reciclaje, la conservación del agua y energía para construir mediante estas prácticas un entorno respetuoso y menos contaminado.

El objetivo es plantear la necesidad y la responsabilidad de integrar dentro del proceso comunicativo estrategias educativas para la sensibilización de la sociedad frente a los problemas ecológicos. Por esta razón, es importante comprender la crisis ambiental que venimos experimentando a nivel mundial 
y así promover costumbres ambientales que contribuyan a una transformación medioambiental.

La comunicación como herramienta educadora impulsará acciones sociales, comprometerá al ciudadano común, haciendo que tome un rol activo frente a la problemática ambiental con el fin obtener soluciones, como bien señala Aparicio (2016). Por ende, es necesario afianzar los pensamientos y acciones mediante la educación ambiental.

Además, es importante mencionar que el proceso comunicativo dentro de la educación ambiental debe ser dialógico y bidireccional, de acuerdo a lo planteado por Oepen (como se citó en Roger \& Buil, 2014, p. 23). Coincidiendo en que la información y todo contenido comunicacional al ser transmitido debe contar con estratégicas que afecten tanto al emisor como al receptor, esto logrará que se comprometan con los temas informados sobre la contaminación y protección ambiental; asimismo, al instruirlos en conciencia ambiental, se formarán hábitos y estilos de vida traducidos en acciones más humanas y respetuosas con el ambiente.

Este tema es un gran desafío, sumamente relevante para la actual crisis ambiental que la humanidad ha generado; lo cual requiere repensar nuestros hábitos culturales a favor de la naturaleza. La cultura es un aspecto determinante en la conformación de valores y actitudes frente al medio ambiente (Martínez \& Ramos, 2003). Al abordar el tema de cultura ambiental, el entorno donde vivimos nos afecta, e interfiere para bien o para mal, es conveniente tomar en cuenta el rol de la comunicación como gestora de nuevos paradigmas y modelos de vida, costumbres y actividades a seguir, fomentando la forja de una civilización del respeto y amor plasmado en la sostenibilidad ambiental.

El trabajo por realizar es el de la concientización e información sobre los problemas ambientales mediante la comunicación. La sociedad percibirá la exigencia de habitar en un entorno saludable acorde con la madre naturaleza. Emprender una cultura ambiental tendrá resultados positivos en el bienestar social. 
Por consiguiente, es de vital importancia la comunicación como instrumento de cambio en la problemática ambiental, destacando la necesidad de implementar estrategias educativas eficaces de comunicación, teniendo como objetivo la concientización en problemas ambientales y el cambio de conducta promoviendo una cultura solidaria y respetuosa por el medio ambiente. Es prioritario el compromiso de la sociedad en la reconstrucción de nuestro planeta e insistir en la educación como la forjadora de seres humanos respetuosos de la vida y del entorno natural.

\section{Referencias}

Aparicio, R. (2016). Comunicación ambiental: aproximaciones conceptuales para un campo emergente. Comunicación y sociedad, 25, 209-235. Recuperado de http://www.scielo.org.mx/ scielo.php?script=sci_arttext\&pid=S0188-252X2016000100009\&lng=es\&tlng=en

Carabaza, J. (2006). Apuntes para comprender la cultura ambiental desde la comunicación. Global Media Journal, 3(6), 86-105. Recuperado de https://journals.tdl.org/gmjei/index.php/GMJ_El/article/view/100/98

Martínez, P. B., \& Ramos, A. M. (2003). Cultura ambiental y la construcción de entornos de reproducción social en Cuba: un reto para el siglo 21. III Conferencia Internacional: La obra de Carlos Marx y los desafíos del Siglo XXI. La Habana, Cuba.

Méndez, L. H. (2014). La cultura como concepto semiótico: Algunas reflexiones metodológicas útiles al pensamiento sociológico. Ciudad de México. México: Ediciones y Gráficos Eón.

Quiroz-Velasco, M. T. (1997). Propuestas para la educación y la comunicación. Comunicar, 4(8), 31-38. Recuperado de https://www.revistacomunicar.com/ojs/index.php/comunicar/article/view/C08-1997-07

Roger, O., \& Buil, P. (2014). Manual de comunicación ambiental. Navarra: Ediciones Universidad de Navarra, S. A.

Sociedad Peruana de Derecho Ambiental. (2006). Ley № 28611, Ley General del Ambiente. Texto concordado (Edición oficial). Lima: SERINSA Industria Grafica. Recuperado de https://spda.org.pe/?wpfb_dl=70 